\title{
PROPUESTAS DE LECTURAS Y PRÁCTICAS DEVOTAS PARA MUJERES EN EL SIGLO XV*
}

\author{
POR \\ ARTURO JIMÉNEZ MORENO ${ }^{1}$ \\ IES San Isidro (Talavera de la Reina)
}

\section{RESUMEN}

Los textos religiosos dirigidos a mujeres durante el siglo XV tienden a repetir algunos contenidos comunes relacionados con el comportamiento femenino, pero también con sus prácticas devotas o su espiritualidad. Se trata de textos de naturaleza y procedencia diversa que anticipan algunas de las propuestas que, a partir de las reformas cisnerianas, se dan en la España de la siguiente centuria. En general, los textos analizados pretenden controlar tanto los tiempos como las lecturas o las formas de devoción de la mujer laica y religiosa.

PALABRAS CLAVE: formas control de la mujer en la España bajomedieval; literatura religiosa del siglo XV; religiosidad femenina; lectura en el siglo XV.

\section{READINGS PROPOSALS AND DEVOTIONAL PRACTICES FOR WOMEN IN THE 15TH CENTURY}

\author{
ABSTRACT \\ 15th century. \\ Recibido/Received 16-05-2018
}

Religious texts addressed to women during the fifteenth century tend to repeat some common content related to female behavior but also to their devotional practices or spirituality. These are texts of diverse nature and origin that anticipate some of the proposals that, from the cisnerianas reforms, occur in the Spain of the following century. In general, the analyzed texts intend to control both the times and the readings or the forms of devotion of the lay and religious women.

KEY WORDS: control of women in late medieval Spain; religious literature of the 15th century; female religiosity; reading in the

Cómo CITAR ESTE ARTículo / CitATION: Jiménez Moreno, Arturo. 2020. «Propuestas de lecturas y prácticas devotas para mujeres en el siglo XV». Hispania Sacra LXXII, 145: 105-114. https://doi.org/10.3989/hs.2020.008

\section{INTRODUCCIÓN}

Es bien conocido el programa espiritual reformista que, a partir de Cisneros, la Iglesia y la monarquía implantaron en la España de los siglos XVI y XVII (Bataillon 1998, 1-71; García Oro 1971 y 1980, 286-290). El incremento en el

Este trabajo se enmarca dentro del proyecto I+D del programa estatal de fomento de la investigación Científica y Técnica de Excelencia «Emergencia de la autoridad femenina en la corte y el convento (Castilla, 1400-1500)» co-dirigido por María Morrás, Departamento de Humanidades, Universidad Pompeu-Fabra (Barcelona), financiado por el MINECO (Ref. FFI2015-63625-C2-1-P).

1 arjimen@hotmail.com /

ORCID iD: https://orcid.org/0000-0002-4770-7690 número de lectores (Lawrance 1985), la mayor accesibilidad al libro gracias a la imprenta (Norton 1997, 185-192; Lopez-Vidriero y Cátedra 1995) y la intención del poder de encauzar y controlar tanto las prácticas devotas como la espiritualidad de religiosos y laicos por medio de un programa de lecturas espirituales - también de la predicación, la confesión y otras vías orales - fueron algunos factores que condicionaron la vida religiosa en los inicios de la Edad Moderna. ${ }^{2}$

Este programa de reformas no pudo surgir sin unos antecedentes que, a lo largo del siglo XV, fueron eclosionando

\footnotetext{
2 A las lecturas espirituales y a sus lectores durante los siglos XVI y XVII ha dedicado un excelente estudio Freitas Carvalho (2007).
} 
unos en las salas y capillas monárquicas y nobiliarias, otros en conventos, frecuentemente dentro de un contexto femenino. ${ }^{3}$ Por ese motivo, me propongo examinar una serie de textos religiosos del siglo XV dirigidos a mujeres para extraer y analizar coincidencias en sus mensajes que nos permitan sostener la hipótesis de que a lo largo de ese siglo - especialmente en su segunda mitad- fueron surgiendo ideas, motivos o consignas que pretendían encauzar o controlar las prácticas devocionales y la espiritualidad femeninas. ${ }^{4}$ En otras palabras, mi objetivo consiste en averiguar si textos de naturaleza y procedencia muy diversas coinciden en la propagación de un mensaje ortodoxo - en esencia, el papel subsidiario de la mujer y el control de su comportamiento o de su religiosidad- $y$, por añadidura, si podemos encontrar matices y excepciones.

Se trata de algo parecido a lo que mostró Pedro Cátedra en su estudio sobre los conventos castellanos femeninos del $X V{ }^{5}$ Vio cómo se estaban introduciendo cambios en la vida conventual que afectaban, entre otros aspectos, al tipo y a las formas de lecturas tanto comunitarias como individuales. ${ }^{6}$ Así, el uso de la lengua romance, de la poesía, de las representaciones dramáticas pero también de las lecturas en común con un cierto grado de ritualización o performance, de la prosa enriquecida con isocolon y rimas o de algunos rasgos de estilo como las oraciones exclamativas, las metáforas amorosas a lo divino contribuirán a crear un marco de desarrollo para una nueva espiritualidad, dirigida en buena parte a un destinatario femenino. ${ }^{7}$

A pesar de que el Duodenarium de don Alfonso de Cartagena, tanto por destinatario como por propósito, queda fuera del objetivo de mi trabajo, sin embargo, el testimonio sobre la mujer de este humanista, religioso, embajador y cortesano vinculado a varios monarcas castellanos puede servir de referencia autorizada. A lo largo de su cuarta quaestio en respuesta a Pérez de Guzman - Quis

3 Ya Eugenio Asensio llamó la atención sobre la influencia - que viene del siglo XV - del franciscanismo y de los conversos en la espiritualidad española renacentista (Asensio 2000); del mismo modo Beltrán de Heredia detectó contactos entre dominicos españoles y el savonarolismo procedente de Italia (Beltrán de Heredia 1972, 520-531). Más recientemente Robinson (2013) ha analizado textos devocionales castellanos del siglo XV - muchos de ellos compendios anónimos o libros de horas, aunque también utiliza alguna de los obras utilizadas en mi trabajo- que apuntan a una influencia de la mística sufí y hebrea en la manera de trasmitir la Pasión de Cristo y la actitud de la Virgen que evita la narración de los sufrimientos físicos y el dolor para centrarse en la divinidad de Cristo y María con el fin de convertir a los judíos y musulmanes peninsulares.

4 Aunque en otro sentido y desde una perspectiva europea, también Sanmartín Bastida (2012) dedica su estudio a explicar el contexto medieval a partir del que surgieron visionarias como Sor María de Santo Domingo.

5 Además de libros de visitas, inventarios y otra documentación, Cátedra descubrió testimonios literarios inéditos - como el Cancionero musical de Astudillo- que hay que relacionar, por ejemplo, con el Libro de devociones y oficios de sor Constanza de Castilla, con la Representación de Nacimiento de Nuestro Señor de Gómez Manrique o con la Vita Christi de Isabel de Villena (Cátedra 2000 y 2005).

6 También se leyeron vidas y testimonios visionarios de religiosas como parte de la formación espiritual en conventos femeninos y masculinos de los siglos XIII y XIV (Sanmartín Bastida 2012, 42).

7 A encontrar explicaciones a la emergencia de algunas de estas manifestaciones literarias durante el siglo XV se han encargado trabajos fundamentales como los de Darbord (1965, 15-25) o Whinnon (1994). mirabilior, laudabilior ac melior reputari debet, optimus vir an optima mulier? (Fernández Gallardo y Jiménez Calvente 2015,384 ) - el obispo de Burgos nos va dando ciertas pistas sobre lo que puede ser considerado ortodoxo en relación a la mujer o no.

\section{EL CORPUS DE TEXTOS}

La mayor parte de los textos religiosos escritos durante el siglo XV -entre ellos muchos breviarios, salterios y libros de horas de carácter anónimo- fueron dirigidos a un público lector y culto, sin marcas genéricas, por lo que sus mensajes carecen de la especificidad que busco. Así, pues, me centraré en aquellos textos que de forma explícita se dirijan a mujeres, tanto laicas como religiosas, y que, además, contengan un mensaje religioso con orientaciones devocionales, doctrinales o espirituales. Me he servido de una muestra representativa de piezas que van desde los tratados extensos destinados a una mujer concreta para dirigir sus prácticas devotas o para formar su religiosidad que son los más ricos en información - hasta piezas breves - cartas, por ejemplo- que tangencialmente dejan algún mensaje a sus destinatarias. La propia tipología textual manejada también nos da luz sobre las formas de devoción y enriquecimiento espiritual de las destinatarias. Así, por ejemplo, el contenido de las cartas que familiares o religiosos envían a monjas no solo nos va a aportar pistas sobre el mensaje transmitido, sino que, además, las cartas mismas representan una vía más en su instrucción religiosa.

Las destinatarias de estas obras son tanto religiosas como damas de la monarquía o de la nobleza. Esta distinción no es, en sí misma, relevante puesto que muchas de las mujeres que entraban en religión pertenecían a familias nobles; y bastantes mujeres nobles casadas y viudas decidían llevar una vida penitencial en un convento de forma más o menos oficial, más o menos permanente. Además, un mismo consejero espiritual - como en el caso de Hernando de Talavera- podía dirigir sus advertencias a una dama particular o un convento. Así, por ejemplo, el mismo fomento de un determinado tipo de devoción - planificado desde la corte isabelina a partir de 1480- y que presenta implicaciones tanto en la literatura (Cátedra 2005) como en las imágenes religiosas (Pereda 2007) puede dirigirse a una mujer laica o a las monjas de un convento. Lo que sí me parece más destacable - por su repercusión en el mensaje- es la naturaleza individual o colectiva de sus destinatarias. En este caso, el mensaje dirigido a un grupo de monjas busca ordenar su vida conventual de acuerdo con los principios de la reforma monástica, mientras que el dirigido a una dama individual tiende a controlar su comportamiento, sus prácticas devotas y, en última instancia, su espiritualidad. Otro asunto, todavía por investigar, es la difusión de esas orientaciones individuales en los círculos espirituales formados alrededor de una determinada corte monárquica o nobiliaria.

El conjunto de obras consultadas, aunque no pretende ser exhaustivo, sí puede considerarse una muestra representativa de la literatura religiosa dirigida a mujeres. Desecho el uso de determinados títulos porque, aunque van destinados a mujeres y presentan un contenido religioso, no contienen un mensaje doctrinal relevante para influir en ellas. Me 
refiero a obras como el Título virginal de nuestra Señora de Alfonso de Fuentidueña escrito a petición de doña Brianda Manrique - por ser más un tratado teológico que doctrinal o devocional- o el Vencimiento del mundo de Alfonso Núñez de Toledo dirigido a doña Leonor de Ayala. ${ }^{8}$

\section{LA DISTRIBUCIÓN DEL TIEMPO DE LA MUJER}

En los textos aparece una preocupación compartida -sobre todo en los tratados más extensos- por controlar el tiempo y los tiempos de las mujeres. Algunos autores proponen una distribución de las horas del día, bien para establecer claramente los momentos de oración en el caso de religiosas, bien para evitar la excesiva ociosidad femenina lo que podría inducir a pensamientos pecaminosos-, bien para rentabilizar el tiempo en el caso de damas poderosas y ocupadas en sus negocios. Creo, además, que en algunas de estas propuestas de organización de cada jornada no podemos descartar un propósito de control del comportamiento femenino tanto dentro como fuera del convento.

En el capítulo IX de su Vita Christi Isabel de Villena describe la vida cotidiana de oración de María tras ingresar en el templo como modelo imitable para las monjas de su propio convento (Villena 1992, I: 230). Así, establece seis actividades que se corresponden con las horas canónicas: contemplaciones (de media noche al alba), oraciones vocales (del alba a tercia), labores comunitarias (de tercia a nona), oración y lectura (de nona hasta la cena), labores comunitarias (tras la cena hasta vísperas) y, otra vez, contemplaciones (desde vísperas hasta la hora de dormir).

Para una dama noble y casada - doña Leonor Pimentel, condesa de Plasencia-, que, además, se dedica a gestionar su linaje y, de paso, parte de la política castellana, su confesor Juan López de Salamanca no puede fijarle un horario pero sí insiste en la necesidad de reservar algún momento del día para la lectura y la oración meditativa:

Escogerás tiempo en que leas e horas çiertas en que contenples lo que leíste, e momentos señala en que fagas lo que estudiaste. Abre tus libros, conpón tus estudios. Tu oraçión sea devota e cabo de lecçión. E tu lecçión sea intenta e cabo de tu oraçión. Sea reposo de tu oración la lecçión; e de la lecçión sea descanso tu oraçión (López de Salamanca 2009, 42).

También en su Jardín de nobles doncellas, escrito en 1468 (Gómez Redondo 1998-2007, IV: 3661-3662), fray Martín de Córdoba aprovecha su defensa de la mujer para ofrecer a la reina Isabel una lista diaria de tareas devotas y espirituales para una dama con poder:

Así, si todas las mugeres deven ser de esta guisa, por devoción a Dios obsequiosas, quánto más deven ser las reinas e princesas [...]; oír cada día sus misas, rezar sus horas e devociones, oír sermones e palabras de Dios; hazer que lean delante della quando comen, e quando están retraídas, lecturas honestas e santas; conversar con letrados e sabios que la pueden dotrinar

8 El listado de obras consultadas aparece al final de este trabajo. Aunque voy a centrarme en el siglo XV, es inevitable no penetrar en los primeros años del siglo XVI. Cisneros y sus propuestas de reforma del clero y de la espiritualidad al amparo de Isabel I ponen los límites ante quem. de cosas divinales; pensar siempre en la otra vida e en quanta que a Dios ha de dar tan estrecha; hablar e oír hablar de la gloria del Paraíso (Córdoba 1964, 89b).

Pero es fray Hernando de Talavera quien dedica uno de sus opúsculos a la distribución del tiempo diario de la condesa de Benavente, doña María Pacheco. ${ }^{9}$ Talavera distribuye el día a la condesa en tres partes: la mañana, el mediodía y la noche. Las mañanas deben dedicarse al rezo - especialmente de las horas de Nuestra Señora-, a oír misa y a conceder audiencia, sobre todo a los más necesitados. Ya al mediodía, tras la comida, aconseja media hora de recreación basada en charlar, escuchar música u oír una lectura. Tras otra media hora de siesta - que en verano se puede alargar-, le propone aislarse dentro del retrete de la condesa para rezar ante el oratorio. Tras el rezo, la dama puede dedicarse a labores de costura, entre las que cabe destacar la confección de «cordones y trenzas de registro para misales» (Talavera 1911, 103). Despachar negocios con el mayordomo, supervisar la marcha de la casa y la educación de los hijos completan la tarde. Tras la cena -entre las siete y las ocho- y media hora de rezo en el oratorio, le aconseja dedicarse a la recreación basada en la lectura y en hacer examen del día antes de dormir.

\section{CONTRA LA OCIOSIDAD Y LOS PENSAMIENTOS IMAGINATIVOS}

Uno de los peligros de la mujer medieval consistía en su tendencia a los pensamientos imaginativos, favorecidos por una excesiva ociosidad, de ahí la importancia del control del tiempo de la mujer. Así se lo confiesa Teresa de Cartagena a doña Juana de Mendoza al principio de su Arboleda de los enfermos:

Pues la soledat no puedo apartar de mí, quiero fuir de la vçiosidat porque non pueda trauar casamiento con la soledat, ca sería un pelygroso matrimonio. [...] Pues así es que esta tan esquiva e durable soledat apartar de mí no puedo, quiero hazer guerra a la [o]cçiosydat ocupándome en esta peque[ñ]a obra (Cartagena 1967, 67).

La mujer debía estar ocupada en sus labores: coser y rezar. Al principio de la Letra para su hija monja (Pulgar 1958, II: 92-113) Fernando del Pulgar le describe pormenorizadamente los inconvenientes de las cosas del mundo, especialmente los del matrimonio, porque no quiere que su hija, que debió de ingresar casi de niña, se deje vencer por los pensamientos imaginativos que la apartarían de su consagración a Dios:

Y pues por la gracia de nuestro Redentor has fecho profesión en la santa religión que escogiste, verdad es que yo no puedo saber cómo te va allá, pero quiérote decir cómo te fuera acá si esta otra vía escogieras [...] Lo primero que te conuenía facer era entrar en la orden del matrimonio, la cual ordenó Dios [...]; pero no entiendas que en buscar marido a la fija, ni aun después de hallado sea pequeño cuidado a los padres y a la fija (Pulgar 1958, 94-97).

9 Se trata del tratado De cómo se ha de ordenar el tiempo para que sea bien expendido. Avisación a la virtuosa e muy noble señora doña María Pacheco, condesa de Benavente (Talavera 1911), al que dedica certeras páginas Gómez Redondo (2012, I: 798-801). 
Debió de preocupar a Hernando de Talavera la ociosidad femenina como engendradora de malos pensamientos tanto en las monjas como en las seglares. A las monjas del monasterio de San Bernardo de Ávila les advierte: «Ved, hermanas muy devotas, que nunca el Demonio vos halle octiosas, mas que siempre seáis muy bien occupadas, o en cosas spirituales, orationes, lectiones y sanctas amonestactiones, o en obras corporales, provechosas más que hermosas» (Codet 2012, 40).

En su Colación muy provechosa Hernando de Talavera previene contra la ociosidad entre las mujeres de posición elevada:

Mucho debe ser huida de todo fiel cristiano la ociosidad porque, como dize el Sabio, enseña muchos males [...] E aun las reynas y dueñas, grandes y pequeñas, mucho deven mirar que no coman su pan ociosas, mas que siempre sean bien ocupadas, hazendosas y aliñosas, como escribe largamente Salomón de la muger fuerte y preciosa (Parrilla 2014, 115 y 116). ${ }^{10}$

\section{LA JUVENTUD, EDAD DE TENTACIONES Y DE APRENDIZAJE}

En muchos de los textos manejados, sus autores se refieren a la juventud de la destinataria para advertirle de las tentaciones propias de su edad y - por lo que me interesade la conveniencia de recibir precisamente el mensaje en una edad más propicia para aprender y aceptar sus consignas antes de que el paso de tiempo las convierta en mujeres con mayor autonomía.

Pulgar escribe una carta a su hija - que había ingresado en el convento a los doce años - por lo que posiblemente en el momento de recibir el texto tuviera pocos más. ¿Qué motiva a Pulgar a escribir a su hija? Quizá la añoranza: «se nos conmovieron las entrañas», confiesa el autor que sintieron él y su mujer en el momento del ingreso. Aunque este sentimiento resulta extraño porque, como él mismo confiesa, «pocas palabras te fablé desde que nasciste fasta que, conplida la hedad de doce años, escogiste ser consagrada por la bienaventurança venidera» (Pulgar 1958, 92). Creo, más bien, que la letra de Pulgar persigue convencer a su hija para que no sienta curiosidad o «malas imaginaciones» por las cosas del mundo que no pudo vivir debido a su corta edad, como señalé algo más arriba. Por ese motivo, una buena parte de la carta consiste en enumerar detalladamente los inconvenientes y molestias del mundo - especialmente del matrimonio- así como en justificar las ventajas de la vida conventual. ${ }^{11}$

En sus Loores de san Juan Evangelista, Hernando de Talavera recomienda a la reina Isabel leer cosas espirituales

10 También en su propuesta de distribución del tiempo a doña María Pacheco Talavera le advierte del peligro de la ociosidad: «E así aprovechará la obra de las manos para evitar ociosidad, que, como dice [...] San Jerónimo, es madre e maestra de mucho mal» (Talavera 1911, 100).

11 A través de una analogía con los que corren toros, Pulgar explica a su hija que los que están fuera del convento son como los que corren porque parecen tener libertad pero en realidad no hacen sino huir y tropezar; mientras que la vida conventual es como los que miran los toros desde la talanquera: «Verdad es que no tienen aquella libertad que los del coso tienen para andar por do quieren; pero están seguros de los peligros, estropieços e turbaciones que ven padecer a los que andan por el coso» (Pulgar 1958, 99). por estar «en edad tan prona de plazeres y gozos mundanos» (Parrilla 2014, 139). Sin embargo, dado que uno de los propósitos de fray Martín de Córdoba es justificar la reginalidad de Isabel, en el prohemio de su Jardín, la considera ya preparada para el trono a pesar de su edad: «Por lo qual, aunque nos devamos dolor del ilustrísimo varón hermano vuestro, por quanto lo perdimos, pero de otra parte el dolor se amansa quando vemos la noble infancia vuestra, que en la edad que es, tiene tal olor de florecientes virtudes» (Córdoba 1964, 67b).

Juan López de Salamanca declara abiertamente su objetivo en el prólogo del diálogo mariológico dirigido a la joven pero ya poderosa Leonor Pimentel: «Desseando promover vuestra floresçiente e resplandesçiente moçedat, tanto de virtudes e graçias adornada quanto de preminençias e prerrogativas ya guarnida [...] propuse exarar por extenso un libro» (López de Salamanca 2009, 35).

\section{ELVALOR DE LA VIRGINIDAD Y LOS INCONVENIENTES DEL MATRIMONIO}

Quizá por la juventud de sus destinatarias, en los textos manejados la virginidad se les ofrece asociada a varias virtudes, algunas de ellas bien conocidas desde el principio del cristianismo (Lucas 1983, 19-29; Salih 2001; Evans 2003). Por su parte, Alfonso de Cartagena reconoce que la donceIla y la casada están más predispuestas a guardar su virginidad y su castidad conyugal, respectivamente, que el hombre de ambos estados (Fernández Gallardo y Jiménez Calvente 2015, 392-393). Fray Martín de Córdoba elogia la castidad tanto de la doncella como de la viuda y de la casada en su manual dirigido a la princesa Isabel. Con todo, dada la condición de heredera al trono, fray Martín ofrece a Isabel una salida en caso de viudez: "Pero guardar lealtad al marido desque es finado esto es de honesto, ca la viuda si se casa no peca» (Córdoba 1964, 109b).

Otros planteamientos resultan algo menos ortodoxos como es la propuesta de una virginidad de intención - willful virginitiy - para damas casadas o casaderas de posición elevada con capacidad de iniciativa personal -como fue el caso de Isabel la Católica- a fin de controlar su comportamiento y garantizar su sujeción al marido o a alguna autoridad eclesiástica masculina (Jiménez Moreno 2018).

Ahora me interesa destacar el valor de la virginidad como estado femenino que favorece la contemplación y el amor a Dios, especialmente entre las monjas consagradas. Así, en la segunda carta devocional a una monja del Cancionero de Egerton leemos cómo una virgen, por el hecho de renunciar a la carne, puede sentir mejor la crucifixión de Cristo: "Y a esta contemplación, devota señora, mucho dispone \& aderesça la virginidat que escogistes, porque las vírgines sobre todos tienen cruçificada su carne e por tanto sienten más aina la pasión y el amor del crucifijo» (Severin 1997, 72).

Cuando Pulgar se adelanta a las quejas de su hija consagrada por no haber conocido las cosas del mundo, le pondera las ventajas de la virginidad en comparación con los inconvenientes e incomodidades fuera del convento:

Y si me dixieres que estás ahí encerrada, dígote que así lo están acá las buenas. Y si sientes estar subjeta, así mandó Dios que lo fuesen todas. Si no gozas con la compañía del marido, así estás libre del dolor del parto. Si no gozas con la generación de los fijos, tampoco te 
atormentan sus muertes y sus cuidados. Si caresces de seruidores, así estás libre de buscar lo necesario para los proueer. Si te holgaras con tus iguales, así penaras en sofrir la envidia de tus desiguales. Y en conclusión, si no puedes decir ni facer lo que quieres, así estás libre que no te digan ni te hagan acá lo que no quieres, y de los otros infinitos males que arriba dice Sant Agostín (Pulgar 1958, 107).

\section{IMPORTANCIA DE LA LECTURA}

Los manuales y tratados del período coinciden en hacer recaer sobre la lectura una parte de la educación religiosa de las mujeres o, al menos, de su ocio (Lawrance 1985, 90). Esta coincidencia refleja la incorporación definitiva de la mujer noble al nuevo público lector en la península (Ruiz García 2005; Sabaté i Marín y Soriano Robles 2005; Beceiro Pita 2007, 547-586; Fuente Pérez 2011; Jiménez Moreno 2019)..$^{12}$ El desarrollo de la literatura espiritual centrada en la meditación sobre las figuras de Cristo y de María implica una cierta competencia lectora, por lo que los confesores y directores espirituales - como vimos en la distribución del tiempo- conceden a la lectura un poder de sugestión $-y$ conversión (Robinson 2013, 4) - tan importante, al menos, como las imágenes o la predicación. Frente a esta creciente tendencia, Alfonso de Cartagena advierte sobre el peligro de un excesivo deseo de leer entre los laicos porque puede mover a herejías (Lawrance 1979, 47-49).

Se nos presentan dos modalidades de lectura: la lectura individual, silenciosa y privada, por un lado (Saenger 2004, 255-259); la lectura en voz alta para un grupo de oyentes, por otro (Ruiz García 2005, 106-107). En el convento la primera se practica en la celda y la segunda tanto en el coro como en el refectorio. Las mujeres laicas leen privadamente en sus cámaras y retretes; y escuchan la lectura en los estrados de sus salas, en sus oratorios, en las capillas e iglesias. Cuando Gómez Manrique trata de consolar a su hermana doña Juana sobre el carácter mudable de la Fortuna, utiliza el ejemplo de la caída de Troya en los siguientes términos:

Avnque no por sus estoria aver leído, más siguiera por oídas, será a vos, señora, manifiesta la gloria d'esta nonbrada çibdad troyana [...] De una e de otra parte falleçió gran suma de gentes e de notables caualleros; la enojosa e grosera porfía de algunos de los quales no creo que en la sala de vuestro palaçio algunas vezes no se aya debatido (Manrique 2003, 429-430). ${ }^{13}$

Las finalidades básicas de la lectura entre mujeres son tres, sin contar variantes y casos particulares. La más frecuente es la lectura durante la celebración tanto de la liturgia de la misa como del oficio de las horas. Se trata de una

12 En su regimiento de príncipes orientado a la princesa Isabel fray Martín de Córdoba, además, aconseja a la joven princesa a aproximarse al estudio siguiendo el modelo de mujeres antiguas: «Dizen que la reina de Egipto, doña Iseo, halló las letras egipcianas e otras industrias [...] Otra muy sabia donzella, por nombre ninfa Carmentis e otro nombre Nicostrates, dizen que halló las letras latinas» (Córdoba 1964, 102a); y concluye: «Por lo qual debe catar algunas horas al día en que estudie e oya tales cosas que sean propias al regimiento del reino» (Córdoba 1964, 103b).

13 Fuente Pérez $(2011,95-96)$ recaba otros testimonios de lecturas femeninas en voz alta. lectura repetitiva y superficial en la que el libro debió de servir de guía para ir siguiendo la celebración litúrgica. Una segunda finalidad perseguía fines recreativos, así me parece la lectura durante las colaciones en los refectorios de los conventos o en las salas de los palacios. ${ }^{14}$ En su mayor parte esta lectura recreativa presenta un carácter edificante a partir de las vidas de Cristo, de María o de los santos. Y, por último, podemos incluir un tercer tipo de lectura: la lectura formativa, es decir, aquella que, por propia iniciativa femenina o por la de los confesores, persigue mejorar la formación doctrinal y espiritual de sus destinatarias. Este tercer tipo de lectura es menos frecuente y se puede dar tanto entre religiosas como entre laicas, de las que podemos sospechar una mayor formación y competencia lectora.

En varios opúsculos, Hernando de Talavera declara diversos frutos de la lectura. Así, en su Colación muy provechosa recomienda a la reina Isabel leer vidas de santos porque los gobernantes deben «tener ojo a los excelentes varones de su estado, hábito y profesión, pasados y presentes» (Parrilla 2014, 119). Además, el mismo Talavera encarece las virtudes de las lecturas espirituales especialmente en una reina joven y ocupada como era Isabel:

Ca en edad tan prona de plazeres y gozos mundanos, y en tiempo de tantas tempestades y cargada de continuo de tantos linages de ocupationes y cuidados, quiere y desea - siquiera por algunos momentosleer cosas espirituales que le alunbren e inflamen a conocer y hazer su voluntad y mandamientos (Parrilla 2014, 139).

A la condesa de Benavente, doña María Pacheco, el mismo Talavera le recomienda: "para vuestra avisación devéis expender algo en leer o en oir, y en comunicar algunas veces con personas sabias e espirituales que vos puedan avisar e infomar de cómo vos havéis de salvar» (Talavera 1911, 100). También fray Hernando de Talavera destaca la función de la lectio para "acquirir y conservar la devotion» entre las monjas abulenses de San Bernardo (Codet 2012, 33).

Ya vimos más arriba cómo Juan López de Salamanca trata de distribuir el tiempo de una ocupada Leonor Pimentel proponiéndole la lectura frecuente como fundamento de la oración. De hecho, como pasa con la reina Isabel, los libros de su biblioteca, así como las obras auspiciadas por ella o a ella dirigidas avalan su competencia lectora (Jiménez Moreno 2019). Entre las tareas propias de las reinas y princesas que, como vimos, enumera fray Martín de Córdoba en su Jardín de nobles doncellas se encuentra la recepción de la lectura en voz alta tanto en público como en privado: "Hazer que lean delante della quando comen, e quando están retraídas, lecturas honestas y santas» (Córdoba 1964, 89).

No obstante, el mismo Martín de Córdoba establece dos niveles de lectura - el más sutil de los cuales no está al alcance de la mujer - cuando, tras recurrir a la autoridad de san Agustín en su defensa de la dignidad del matrimonio en el Paraíso, amaga con un argumento de mayor enjundia: «La otra manera de salvar su dicho es aún más profunda: pero es para la escuela, que no para donzellas, lo uno porque es

14 Recomienda Hernando de Talavera a las monjas abulenses: «En todo tiempo, aya lectión quando tomas la refectión corporal, assí a la cena como a la yantar, y en los días de ayuno a la colaçión» (Codet 2012, 33). 
sutil; lo otro porque no se puede explicar sin palabras vergonçosas» (Córdoba 1964, 82). También Juan López sugiere dos niveles de lectura en la dedicatoria de su Libro de las historias a doña Leonor: «E mírelo vuestra alteza e léalo una vez siquera vuestra devotíssima nobleza por deporte alegre e gozoso, fablando en el retrete con la Madre del Gloriossísimo» (López de Salamanca 2009, 36). Creo que lo que se deduce de esta recomendación es que López de Salamanca concibe una lectura recreativa, esto es, voluntaria y "por deporte»; y otra, de obligado cumplimiento, es decir, la lectura litúrgica o la del rezo diario.

\section{PRopuestas de LECTURA}

Como adelanté al principio, las cartas, los sermones para ser leídos o los tratados y opúsculos empleados en este trabajo son en sí mismas lecturas que seguramente o bien habían pedido sus destinatarias o bien partieron de la iniciativa de sus autores. Salvo algunos textos circunstanciales, podemos considerarlas como lecturas canónicas o, al menos, recomendadas.

Ante todo, conviene señalar que las propuestas de lectura a mujeres que hemos recogido en los textos seleccionados están todas escritas en romance, incluyendo los propios textos manejados. ${ }^{15}$ Pulgar traslada «de latín en romance la oración dominica del Pater noster, con la esposición que fizo Sant Agostín» (Pulgar 1958, 113). ${ }^{16}$

Tanto en las bibliotecas conventuales como en las nobiliarias no suele faltar una Vita Christi - uno de los textos más influentes en la espiritualidad franciscana tardomedieval (Cátedra 2005, 80-81) - y un repertorio de vidas de santos, especialmente el Flos sanctorum, casi obligatorio entre los libros de la nobleza femenina (Baños Vallejo 2010; Beceiro Pita 2007, 287-319) y de amplísima difusión -en sus distintas versiones - en la imprenta de los siglos XV y XVI (Aragüés Aldaz 2012 y 2016). Así, Hernando de Talavera, en su Colación, propone a los religiosos - y a la reina Isabella lectura en voz alta de las vidas de santos:

Por lo qual, nos leen cada día la calenda, en la prima, en que comúnmente se haze memoria en suma, de las excelentes vidas y graves pasiones y gloriosas muertes de los sanctos [...] Y aun por esto, es consejo saludable que leamos espesamente las vidas de aquellos, porque más que otra lectión nos puede inflamar,

15 «Sea siempre la lectión en romance, porque la lectión que no se entiende ni se lee ni se oye como debe, ni aprovecha mucho leerse», aconseja Hernando de Talavera a las monjas (Codet 2012, 33). El Libro de devociones y oficios, un devocionario confeccionado por sor Constanza de Castilla para uso de las religiosas del convento de Santo Domingo el Real de Madrid, emplea la lengua romance aunque mantiene el latín para las antífonas, himnos y lectiones.

${ }_{16}$ Es bien conocido el pasaje donde el mismo Pulgar en su letra para la reina Isabel se interesa por sus progresos con el latín — «mucho deseo saber cómo va a vuestra alteza con el latín que aprendéis»porque reconoce su dificultad - «porque hay algún latín tan zahareño que no se dexa tomar de los que tienen muchos negocios»aunque al final confía en la capacidad de Isabel: «aunque yo confío tanto en el ingenio de vuestra alteza, que si lo tomáis entre manos, por soberuio que sea, lo amansaréis como hauies hecho con otros lenguajes» (Pulgar 1958, 55). En los Evangelios moralizados de Juan López de Salamanca - destinados, al menos en una primera fase, a la condesa de Plasencia- siempre que se cita en latín el texto evangélico va seguido de su traducción al romance.

\section{consolar y esforçar al servicio de nuestro Señor (Parrilla} 2014, 118-119). ${ }^{17}$

Sin embargo, a los gobernantes - solo los cita en masculino- les añade la lectura de vidas de hombres de posición elevada: "No menos reyes y príncipes, duques y marqueses y qualesquier otros señores deven siempre tener ojo a los excelentes varones de su estado, hábito y profesión, pasados y presente» (Parrilla 2014, 212).

Pero es en la Suma y breve donde propone un listado de obras apropiadas para la lectura conventual: vidas de santos, los Morales y Diálogos de san Gregorio, la Vita Christi, el Libro de las donas y De natura angelica de Eiximenis, el De como los novicios han de ser enseñados de Buenaventura, la Regla de san Jerónimo a la virgen Eustochio, el Libro de san Bernardo a su hermana Florentina, el De la vida christiana de san Agustín, el Espejo del pecador, Soliloquio, Colationes de los padres, Instituciones de los monjes y, por último, el Espejo de los legos (Codet 2012, 33-34). Frente a estos libros recomendados, en los inventarios de libros de conventos femeninos del siglo XV nos encontramos - junto a los volúmenes necesarios para las celebraciones litúrgicas, que son mayoría - algunas obras de meditación para la lectura individual (la Doctrina cordis, el Espejo de la cruz de Domenico Calvalca, el Contemptus mundi, por ejemplo) u obras para la lectura comunitaria en el refectorio como santorales y reglas monásticas, fundamentalmente (Cátedra 2005, 75-100).

Como no podía ser de otro modo, las lecturas propuestas de los directores espirituales a las damas nobles son fundamentalmente religiosas. ¿Encontramos en las bibliotecas privadas femeninas este mismo carácter? De entrada, se ha señalado que la materia religiosa parece estar menos representada en las bibliotecas personales de los nobles del siglo XV (Faulhaber 1998, 792-793) que en las de las mujeres (Beceiro Pita 2007, 562-575). Así, la biblioteca de doña Leonor Pimentel está compuesta casi en exclusiva de textos religiosos (Jiménez Moreno, 2019) y lo mismo podemos decir de los libros de uso privado que se encontraban en la cámara de la reina Isabel (Ruiz García 2005, 110-111).

\section{LA ORACIÓN PRIVADA Y LA CELEBRACIÓN DEL OFICIO}

Cuando Pulgar instruye a su joven hija monja sobre la manera de orar, enumera las tres características de la oración: sentimiento, concentración y entendimiento. Le recomienda que su oración se base en el sentimiento de amor a Dios; que no se mezcle con pensamientos ajenos y, finalmente, que se practique con sentido. Por ese motivo, Pulgar termina su letra anunciando a su hija la traducción del padrenuestro de latín al romance con una exposición de san Agustín (Pulgar 1958, 112-113).

Sin salirnos del ámbito de las religiosas consagradas, Hernando de Talavera dedica el capítulo 5o de su Suma y breve a «cómo han de ser cuidosas de decir y hazer muy bien el officio divinal» (Codet 2012, 30-31). Destaca la importancia del oficio dentro de la vida conventual al pedir a las monjas que acudan a él con tiempo, alegres, descansadas y «con

17 En 1473 doña Catalina Núñez de Toledo deja a las monjas del convento de la Visitación de Madrid, entre otros libros, una Vita Christi de Eiximenis, la Infantia Salvatoris y un Flos sanctorum (Cátedra 2005, 77-78). 
apparejado coraçón». También ordena que la iglesia esté preparada para el rezo del oficio con los libros necesarios, las velas encendidas y la iglesia limpia. Además, describe su desarrollo donde destaca la importancia de las voces y del silencio o la concentración en las oraciones para no distraerse ni con la imaginación ni, por supuesto, con hablas innecesarias (Cátedra 2005, 102-106). ${ }^{18}$

Fray Martín de Córdoba destaca tres formas de honrar a Dios: creer solo en Él, no blasfemar y, por último, guardar las fiestas de Dios, María y los santos oyendo misa y rezando las horas (Córdoba 1964, 95b).

Leemos la propuesta más completa sobre las formas de devoción en el Libro de las historias de nuestra Señora de fray Juan López, quien le aclara a doña Leonor la conveniencia de la oración vocal o de una determinada postura corporal según la intención del orante. Juan López aprovecha la respuesta de María a una pregunta del personaje de la Condesa sobre sus ocupaciones mientras visitaba a su prima Isabel para tratar sobre el concepto de devoción y proponer algunas prácticas devotas.

Como en los casos de Pulgar y Talavera, cuando fray Juan explica a doña Leonor qué es devoción también lo relaciona con el sentimiento amoroso que requiere lágrimas y ternura; y contiene, además, celo, compasión y benevolencia (López de Salamanca 2009, 369). Distinguen tres formas de devoción: una relacionada con el rezo del oficio, que pertenece a los clérigos; otra es la contemplación, propia de los religiosos; y finalmente la oración personal, que es la destinada a los seglares (López de Salamanca 2009, 371). Contra lo esperable, Juan López decide explicar a la condesa cómo debe oír el oficio divinal porque, según pone en boca de la condesa, suele acudir a rezar el oficio: «Puesto que yo sea seglar e lega, e, ocupada de negoçios, no pueda entender en la devoçión del cantar del ofiçio divinal, pero en la mi capilla, a honor de Dios e serviçio de vos e de los santos otros, se dize el ofiçio divinal e yo me presento a lo oír» (López de Salamanca 2009, 371). ${ }^{19}$

Según Juan López, el oficio debe rezarse evitando la rutina del "uso y costumbre» y procurando entender el sentido de las palabras, como ya le había advertido Pulgar a su hija; además en el canto litúrgico debe mostrarse una alegría moderada, aunque respetando la reverencia debida. ${ }^{20}$ Por último, escuchar el oficio requiere una actitud humilde pero sin parecer constreñidos por el miedo (López de Salamanca 2009, 372-373). La propuesta de Juan López parece equilibrada y alejada de actitudes excesivamente rigoristas: hay que entender y gozar de la celebración del oficio pero con mesura. La condesa toma la palabra para lamentarse de los impedimentos que la apartan de celebrar

18 El Livro dos Ofícios da Ordem del monasterio de Nossa Senhora de Évora (conservado en un manuscrito de 1537, pero recoge una adaptación tardomedieval de la regla dominica a los conventos femeninos, Biblioteca Nacional do Portugal, Iluminados, no 152) establece que una de las cantoras debía encargarse tanto de la convervación como de la corrección «no canto, letra, pontos e açentos» de los libros litúrgicos (fol. 60r).

19 Por el inventario de sus bienes sabemos que Leonor Pimentel disponía de cantores, libros de canto de órgano, facistoles e incluso un órgano de fuelles (Jiménez Moreno 2019, 27).

20 Critica la falta de compostura «ca muchos cantan e oen al ofiçio divinal con alegría, mas es dissoluta e quasi seglar, de risa e burla toda revestida, como pareçe en los ofiçios en que se cantan chançonetas desonestas e fazen moharraches» (López de Salamanca 2009, 372). el oficio debidamente: las charlas, los negocios mundanos, las visitas de otras mujeres, las interrupciones de los hijos o los pensamientos que van y vienen (López de Salamanca 2009, 373). Creo que Juan López nos está describiendo el ambiente cotidiano durante el rezo del oficio en la iglesia o en la capilla del palacio ducal en Plasencia: mujeres que secretean, niños que entran y salen de la capilla, sirvientes que interrumpen para consultar tal o cual asunto...

Frente a todo este ruido, tanto Juan López como otros escritores proponen la soledad y el silencio como propicios para la oración, lejos de las "fablillas mundanas», de las "consejuelas profanas» o de las «patrañuelas vazías» de las damas y sirvientas de su palacio; pero lejos también de los «negoçios de su señoría» o de los «estruendos» de su casa. ${ }^{21}$ Del mismo modo, en su Arboleda de los enfermos Teresa de Cartagena reconoce que su molesta sordera al menos le facilita el acercamiento a Dios porque queda aislada de las voces del mundo: "Por cierto, grand provecho deuen estas palabras por las quales oyrán plaziendo a Dios de así quitar todos los ynpedimentos y estorvos. Ya soy apartada de las bozes humanas, pues mis orejas no las pueden oír» (Cartagena 1967, 43).

$Y$, según describe Isabel de Villena, lo primero que hace María cuando ingresa en el templo a los doce años es encerrarse en su celda: «E, restant sa senyoria sola, partida la virtuosa Anna, sa merçe tancà la porta, e, agenollant-se davant una finestra que mirava al cel, e dix ab moltes lagrimes e singular devocio» (Villena 1992, II: 230).

Juan López sigue utilizando a la Virgen para instruir a Leonor sobre la forma de oír el oficio. Así, le sugiere asuntos sobre los que meditar. ${ }^{22}$ Añade qué cantos y salmodias son los adecuados no solo para practicar en público sino también "ya retraída en tu oratorio o en el ofiçio divinal» (Jiménez Moreno 2009, 379). A continuación, la condesa se pregunta sobre el tipo de oración más apropiado: mental o vocal. La Virgen responde enumerando las ventajas de la oración en voz alta - «clamando»- porque es la más apropiada para pedir ayuda ante las tribulaciones, ante las agresiones o ante los peligros - quizá las circunstancias en las que solía moverse Leonor en su vida pública- así como para satisfacer alguna necesidad.

Juan López dedica varias páginas a describir e interpretar minuciosamente "cómo se deve sus mienbros e cuerpo ordenar en sus oraçiones privada e comunes» (López de Salamanca 2009, 382-384). ${ }^{23}$ Creo que lo que el fraile domi-

21 Es posible que Juan López no solo esté buscando una predisposición espiritual de doña Leonor hacia la lectura de su obra sino también esté intentando apartarla de actividades públicas más propias de varones. El texto ocupa el capítulo II del Libro de las historias de nuestra Señora cuya rúbrica dice: «Cómo la condesa aparta de sí todos estruendos que le pueden enpedir su intento» (López de Salamanca 2009, 37).

22 Además de meditar sobre Dios o los sufrimientos de Cristo, sobre las propias culpas sobre las buenas obras, Juan López concluye que estas meditaciones "algunas personas de fazienda que han espaçiosas vacaciones en alguna parte del día las devrían praticar» (López de Salamanca 2009, 376).

${ }_{23}$ El recelo de las autoridades eclesiásticas ante una excesiva manifestación externa en la religiosidad de las mujeres - especialmente en el lenguaje corporal de las místicas y visionarias- puede explicar esta recomendación de buscar su apartamiento durante el rezo o el encauzamiento de las distintas posturas corporales (Sanmartín Bastida 2012, 78-79). 
nico le está proponiendo a su hija espiritual es la adaptación de alguna versión de lo que se conoce como los modos de orar de Santo Domingo de Guzmán, dirigido originalmente a los frailes de la orden (Galmes y Gómez 1987, 195-217 y sobre todo Fueyo Suárez 2006). ${ }^{24}$ Se trata de la enumeración de quince posturas corporales distintas en las que la posición del cuerpo, las manos y la cabeza encierran otros tantos significados de la oración, autorizados por una cita bíblica. Al final, Juan López recomienda a la condesa la postura adecuada para una «hembra seglar en grand señoría establecida, en muchos negoçios ocupada». Se trata de una postura básica y completa («modo mixto o mezclado de orar») porque combina humildad, buena intención y declaración de deseos: "Poner las rodillas en tierra, las manos juntas delante tus pechos, la cabeça levada con ojos al çielo» (López de Salamanca 2009, 385). Por último, la Virgen encarece el rezo del padrenuestro por su autoridad y brevedad (López de Salamanca 2009, 385-386).

\section{LAS DEBILIDADES FEMENINAS}

En su argumentación sobre la preeminencia del hombre o de la mujer, Alfonso de Cartagena atribuye a cada sexo unas virtudes determinadas sin establecer superioridad entre ellas. Así, concede en el hombre una mayor fortaleza física y aguante emocional (Fernández Gallardo y Jiménez Calvente 2015, 388-389), aunque -por el ejemplo de Susana - también sabe valorar la fortaleza viril en la mujer (Fernández Gallardo y Jiménez Calvente 2015, 416-417).

En la misma línea, en una segunda carta devocional del Cancionero Egerton su autor establece diferencias entre las funciones de religiosos y de religiosas. Mientras los primeros, por ser más fuertes, están mejor preparados para salir al mundo a luchar por la Iglesia de Dios con su predicación y sus lecciones; la debilidad de las mujeres - que no podrían soportar las distintas circunstancias que les depara el mundo- las hace más idóneas para la contemplación encerradas en sus conventos. Se parte, claro es, de que, a diferencia del hombre, la mujer religiosa no está preparada para soportar el contacto con el mundo:

O señora, qué grande bien vos fizo Dios a las mujeres en la santa conteplación tan apartada, tan secreta, tan quieta, tan deleitosa, e sabes por qué, que no tenedes tantos colores para vos apartar destos abrazos como los omnes que nos sacan a enseñar, a predicar, a castigar, a gobernar e aun a guerrear en las órdenes de la caballería corporal. Buenos actos son, mas requieren varones perfectos que no se derramen, que no se estraguen adobando a los otros que tales se estén en la plaza como en la cámara así fuertes contra los soberbios que queden blandos a los humildes, así discurran andando por el mundo e con el mundo que estén quietos en su espíritu como si estoviesen encerrados, que vean e non cobdicien, que oyan contra sí mesmos e non lo sientan como non deven (Severin 1997, 73).

Esta diferencia hace que las mujeres que quieran desarrollar su espiritualidad necesiten más la soledad y el

24 La misma condesa declara: "Mira cómo los santos varones tovieron muchas maneras de orar corporalmente segúnd diverssos motivos que fallavan en su mente» (López de Salamanca 2009, 384). aislamiento que los hombres, como ya vimos. Así lo sigue indicando la segunda carta devocional:

Ninguna destas ocasiones de apartamiento de la conteplación tenedes vosotras, ca el broslar \& el filar non es abto que quiere mucha conpaña para salir de la sonbra deste árbol de la vera cruz del jardín de tal arboleda, de tal verdura donde oyerdes cantar aquel dulce ruiseñor, como demanda por nos en quanto omne perdón al Padre según la divinidat como encomienda aquella bendita Madre \& Virgen al virgen Sant Juan (Severin 1997, 74)

Este aislamiento del mundo favorece la contemplación $y$, a través de ella, el conocimiento de Dios, pero no a través del estudio o la predicación, más propio para la entereza del religioso, sino del aislamiento:

Piensa, deuota virgen, que no se alcança el fruto deste árbol disputando en las escuelas, rreboluiendo los libros, afeytando las palabras, edificando grandes edificios para orar, faziendo grande aparejos de ornamentos \& rretretes pintados para contemplar, avnque todo esto sea bueno en sus tienpos. Pero más aína se goza mirando, marauillando, callando, apartádose de lo público, del bolliço \& del negosçio seglar, sinón quando la obidiençia manda \& la caridat rrequiere. 0 señora, qué grande bien vos fizo Dios a las mugeres en la santa contenplaçión tan apartada, tan secreta, tan quieta [...] como los omnes que nos sacan a enseñar, a pedricar, a castigar, a gouernar \& avn a guerrear (Severin 1997, 73). ${ }^{25}$

Esta segunda carta nos da todavía otro rasgo de la espiritualidad femenina: la preferencia por un discurso sencillo que llegue al corazón, alejado de cláusulas, divisiones y uso de autoridades confirmantes más propios de un tratado escolástico solo al alcance de religiosos instruidos:

E porque el pensar de Nuestro Señor con algún amor para despertar la devoción no requiere forma escolástica para que vaya polido de palabras, distinto en orden de capítulos, actorizado por glosas \& dichos de doctores. Ca el pensamiento del amor non cura que vaya en orden [...] Así no curé de tener la péñola sino dexarla correr (Severin 1997, 76). ${ }^{26}$

Sor Isabel de Villena en su Vita Christi - frente a, por ejemplo, la versión de Eiximenis- utiliza más el estilo directo que el narrador por lo que su discurso se hace más fluido al poner en boca de la Virgen o de algunos de los personajes exclamaciones fervorosas o autoridades confirmantes que, en otras versiones, debe proclamar un narrador externo (Barnett 2006, 35-36). Da un paso más Juan López de Salamanca en su Libro de las historias de nuestra Señora al usar, más que el estilo directo, la forma dialogada tanto para hacer su discurso más cercano a su destinataria como

25 Algo después Cisneros propondrá la publicación de biografías de visionarias como Ángela de Foligno o santa Catalina de Siena como modelos de mujeres que han adquirido su sabiduría no a través del estudio, como en el caso de los hombres, sino por ciencias infusa (Howe 2002, 284-285; Sanmartin Bastida 2012, 121). Con todo, este conocimiento infundido en las mujeres directamente por la divinidad no estuvo exento de recelo por las autoridades eclesiásticas (Sanmartín Bastida 2012, 37-82).

26 No obstante, la primera carta del mismo Cancionero de Egerton —-también dirigida a una mujer - sí está escrita con algunos rasgos propios del estilo escolástico: uso de autoridades patrísticas o divisio per verbum de un concepto. 
para introducir la voz autorizada de María: «Será la escripta lectura por manera de fabla entre dos perssonas de sexu feminino, de las quales la una pregunta como disçípula afectuosa de aprender, la otra, como maestra ganosa de enseñar e responder» (López de Salamanca 2009, 36).

\section{CONCLUSIÓN: HACIA EL CONTROL DE LA RELIGIOSIDAD FEMENINA}

Los asuntos seleccionados en los textos que nos han servido de referencia no son, por supuesto, los únicos toda selección esconde un cierto sesgo metodológico-, pero sí nos muestran varios procesos que ocurren a medida que avanza el siglo XV. Por un lado, la lectura $-\mathrm{y}$ con ella la confección y circulación de manuscritos - se va consolidando como una de las vías frecuentadas por la aristocracia femenina para su instrucción religiosa. Desde el punto de vista del emisor los textos, se percibe una tendencia por parte de sus autores a controlar la religiosidad femenina. Por último, se pueden distinguir algunos topoi que nos revelan, más que los asuntos y intereses religiosos en la mujer, las preocupaciones de una parte - al menos - de la Iglesia peninsular ante una creciente autoridad femenina en la vida política y religiosa. Por ese motivo, los textos pretenden vigilar distintas dimensiones de la mujer: desde la planificación de sus actividades y tiempos o sus prácticas religiosas externas hasta la orientación de sus creencias, devociones y lecturas. ${ }^{27}$ Creo que estas tendencias en que confluyen intereses religiosos, uso de la lectura y control de la autoridad femenina se van conformando durante el siglo XV y, por el impulso tanto del poder monárquico como de la autoridad religiosa - con la difusión de la imprenta-, se consolida, se unifica y se programa ya desde Cisneros.

\section{FUENTES}

Cartagena, Teresa de. 1967. Arboleda de los enfermos y Admiraçión operum Dey. Ed. Lewis J. Hutton. Madrid: RAE.

Codet, Cécile. 2012. "Edición de la Suma y breve compilación de cómo han de bivir y conversar las religiosas de Sant Bernardo que biven en los monasterios de la cibdad de Ávila de Hernando de Talavera (Biblioteca del Escorial, ms. A.IV-29)». Memoriabilia 14: 1-57.

Córdoba, Martín de. 1964. Jardín de nobles doncellas. En Prosistas castellanos del siglo XV, ed. Fernando Rubio, II, 65-117. Madrid: Atlas.

López de Salamanca, Juan. 2009. Libro de las historias de Nuestra Señora. Ed. Arturo Jiménez Moreno. Salamanca: Cilengua.

Pulgar, Fernando de. 1958. Letras. Glosas a las Coplas de Mingo Revulgo. Ed. Jesús Domínguez Bordona. Madrid: Espasa-Calpe.

Severin, D S. 1997. "Two Letters of Devotional Advice to Nuns in the Cancionero de Egerton (Dutton LB3)». En Spain and its Literature. Essays in Memori of E. Allison Peers, ed. Ann L. Mackenzie, 65-76. Liverpool: Liverpool University.

Talavera, Hernando de. 1911. De cómo se ha de ordenar el tiempo para que sea bien expendido. Avisación a la virtuosa e muy noble señora doña María Pacheco, condesa de Benavente, de cómo se debe cada día ordenar e ocupar para que expienda bien su tiempo. En Escritores Místicos Españoles, ed. Miguel Mir, I, 94-103. Madrid: Nueva Biblioteca de Autores Españoles.

Villena, Isabel de. 1992. Vita Christi. Ed. Josep Alminaña Vallés. 2 vols. Valencia: Ajuntament de Valencia.

27 Se trata de conclusiones parecidas a las que llega Surtz para el caso de Hernando de Talavera y Juan López de Salamanca con respecto a la reina Isabel y a Leonor Pimentel (Surtz 2002).

\section{BibliografíA}

Aragüés Aldaz, José. 2012. «Los Flores sanctorum medievales y renacentistas. Brevísimo panorama crítico». En Literatura medieval y renacentista en España: líneas y pautas, Natalia Fernández Rodríguez y María Fernández Ferreiro, 349-361. Salamanca: Semyr.

Aragüés Aldaz, José. 2016. "La Leyenda de los santos: orígenes medievales e itinerario renacentista». Memorabilia 18: 133-187.

Asensio, Eugenio. 2000. El erasmismo y las corrientes espirituales afines. Conversos, franciscanos, italianizantes con algunas adiciones y notas del autor. Carta prólogo de Marcel Bataillon. Salamanca: Semyr - SEHL.

Baños Vallejo, Fernando. 2010. «Vidas de santos en manos de nobles: mecenas y coleccionistas». En Estudios sobre la Edad Media, el Renacimiento y la temprana Modernidad, ed. Francisco Bautista Pérez y Jimena Gamba Corradine, 61-73. San Millán de la Cogolla: Semyr - Cilengua.

Barnett, David. 2006. «The voice of the Virgin: accessible authorithy in the Visitation episode of Isabel de Villena's Vita Christi». La Corónica 35 (1): 23-45. https://doi.org/10.1353/cor.2006.0040

Bataillon, Marcel. 1998. Erasmo y España. Estudios sobre la historia espiritual del siglo XVI. Madrid: FCE.

Beceiro Pita, Isabel. 2007. Libros, lectores y bibliotecas en la España medieval. Murcia: Nausicaä.

Beltrán de Heredia, Vicente. 1972. «Las corrientes de espiritualidad entre los dominicos de Castilla durante la primera mitad del siglo XVI». En Miscelánea Beltrán de Heredia. Colección de artículos sobre historia de la Teología española, III, 519-671. Salamanca: OPE.

Castilla, Constanza. 1998. Book of Devotions. Libro de devociones y oficios. Ed. Constance L. Wilkins. Exeter: University of Exeter Press.

Cátedra, Pedro. 2000. "Liturgia, poesía y la renovación del teatro medieval». En Actas del XIII Congreso de la Asociación Internacional de Hispanistas, ed. Florencio Sevilla y Carlos Alvar, I, 3-28. Madrid: Castalia.

Cátedra, Pedro. 2005. Liturgia, poesía y teatro en la Edad Media. Madrid: Gredos.

Darbord, Michel. 1965. La poésie religieuse espagnole del Rois Catholiques a Philippe II. Paris: Editions Hispaniques.

Evans, Ruth. 2003. "Virginities». En Medieval Women's Writing, ed. Carolyn Dinshaw y David Wallace, 21-39. Cambridge: Cambridge University Press.

Faulhaber, Charles B. 1998. "Las bibliotecas españolas medievales». En Pensamiento medieval hispano. Homenaje a Horacio SantiagoOtero, coord. José María Soto Rábanos, vol. I, 785-800. Madrid: CSIC - Consejería de Cultura de Castilla y León - Diputación de Zamora.

Fernández Gallardo, Luis y Teresa Jiménez Calvente. 2015. El «Duodenarium» (c. 1442) de Alfonso de Cartagena. Cultura castellana y letras latinas en un proyecto inconcluso. Córdoba: Almuzara.

Freitas Carvalho, José Adriano. 2007. Lectura espiritual en la Península Ibérica (siglos XVI-XVII). Programas, recomendaciones, lectores, tiempos y lugares. Salamanca: Semyr.

Fuente Pérez, María Jesús. 2011. «Virgen con libro. Lecturas femeninas en la Baja Edad Media hispana». Espacio, Tiempo y Forma. Serie III, Historia Medieval 24: 91-107.

García Oro, José. 1971. Cisneros y la reforma del clero español en tiempo de los Reyes Católicos. Madrid: CSIC.

García Oro, José. 1980. "Conventualismo y observancia. La Reforma de las órdenes religiosas en los siglos XV y XVI». En Historia de la Iglesia en España. La Iglesia en la España de los siglos XV y XVI, dir. Ricardo García-Villoslada, vol. III, t. 1, 211-349. Madrid: Biblioteca de Autores Cristianos.

Gómez Redondo, Fernando. 1998-2007. Historia de la prosa medieval castellana. 4 vols. Madrid: Cátedra.

Gómez Redondo, Fernando. 2012. Historia de la prosa de los Reyes Católicos: el umbral del Renacimiento. 2 vols. Madrid: Cátedra.

Howe, Elizabeth Teresa. 2002. "Cisneros and the Translation of Women's Spirituality». En The Vernacular Spirit. Essays on 
Medieval Religious Literature, ed. Renate Blumenfeld-Kosinski, Duncan Robertson y Nancy Warren, 283-295. New York: Palgrave.

Jiménez Moreno, Arturo. 2018. «La virginidad de voluntad como propuesta para la mujer noble casada en algunos manuales castellanos del siglo XV». En Espacios en la Edad Media y el Renacimiento, 635-647. Salamanca: SEMYR.

Jiménez Moreno, Arturo. 2019. Devoción y cultura escrita en el entorno de doña Leonor Pimentel, I duquesa de Plasencia (c. 1435-1486). London: Queen Mary and Westfield College.

Lawrance, Jeremy. 1979. Un tratado de Alonso de Cartagena sobre la educación y los estudios literarios. Barcelona: Universidad Autónoma de Barcelona.

Lawrance, Jeremy. 1985. "The Spread of Lay Literacy in Late Medieval Castile». Bulletin of Hispanic Studies 62 (1): 79-94.

López-Vidriero, María Luisa y Pedro Cátedra. 1995. «La imprenta y su impacto en Castilla». En Historia de una cultura: la singularidad de Castilla, ed. Agustín García Simón, II, 464-542. Valladolid: Junta de Castilla y León.

Lucas, Angela M. 1983. Women in the Middle Ages. Religion, Marriage and Letters. New York: St. Martin's Press.

Manrique, Gómez. 2003. Cancionero. Ed. Francisco Vidal González. Madrid: Cátedra.

Norton, Frederick John. 1997. La imprenta en España 1501-1520. Madrid: Ollero \& Ramos.

Parrilla, Carmen. 2014. Dos escritos destinados a la reina Isabel. "Colación muy provechosa». "Tratado de loores de San Juan Evangelista». Valencia: Publicaciones de la Universitat de Valencia.

Pereda, Felipe. 2007. Las imágenes de la discordia. Política y poética de la imagen sagrada en la España del cuatrocientos. Madrid: Marcial Pons.
Robinson, Cynthia. 2013. Imagining the Passion in a Multiconfessional Castile. The Virgin, Christ, Devotions, and Images in the Fourteenth and Fifteenth Centuries. Pennsylvania: Pennsylvania State University Press.

Ruiz García, Elisa. 2005. «El universo femenino y las letras (siglos XV-XVII)». En Mujer y cultura escrita. Del mito al siglo XXI, coord. María del Val González de la Peña, 97-115. Gijón: Trea.

Sabaté i Marín, Glorìa y Lurdes Soriano Robles. 2005. «Reinas catalanas: mujeres, lectoras y protectoras de la cultura (siglos XIV-XV)». En Mujer y cultura escrita. Del mito al siglo XXI, coord. María del Val González de la Peña, 85-96. Gijón: Trea.

Saeger, Paul. 2004. "La lectura en los últimos siglos de la Edad Media». En Historia de la lectura en el mundo occidental, coord. Guglielmo Cavallo y Roger Chartier, 211-259. Madrid: Taurus.

Salih, Sarah. 2001. Versions of Virginity in Late Medieval England. Cambridge: D.S. Brewer.

Sanmartín Bastida, Rebeca. 2012. La representación de las místicas: Sor María de Santo Domingo en su contexto europeo. Santander: Propileo Press.

Surtz, Ronald E. 2002. "Female Patronage of Vernacular Religious Works in Fifteenth-Century Castile: Aristocratic Women and their Confessors». En The Vernacular Spirit. Essays on Medieval Religious Literature, ed. Renate Blumenfeld-Kosinski, Duncan Robertson y Nancy Warren, 263-282. New York: Palgrave.

Whinnon, Keith. 1994. «The Supposed Sources of Inspiration of Spanish Fifteenth-Century Narrative Religious Verses». En Medieval and Renaissance Spanish Literature. Selected Essays of Keith Whinnon, ed. Alan Deyermond, W. F. Hunter y Joseph T. Snow, 46-71. Exteter: University of Exeter Press. 